\title{
Interpreting Seismic Profiles in terms of Structure and Stratigraphy, an Example from Lower Indus Basin Pakistan
}

\author{
Majid Khan ${ }^{1, *}$, Shahid Nawaz ${ }^{2}$, Munawar Shah $^{3}$, Muhammad Hasan ${ }^{1}$ \\ ${ }^{1}$ Institute of Geology and Geophysics, Chinese Academy of Sciences, China \\ ${ }^{2}$ National Centre of Excellence in Geology, University of Peshawar, Pakistan \\ ${ }^{3}$ Shanghai Astronomical Observatory, Chinese Academy of Sciences, China
}

Copyright $\bigcirc 2016$ by authors, all rights reserved. Authors agree that this article remains permanently open access under the terms of the Creative Commons Attribution License 4.0 International License.

\begin{abstract}
Structural delineation and Stratigraphic evaluation of proven geological basins are of prime importance for hydrocarbon exploration and exploitation. The current study aims to map the subsurface geology in a part of Lower Indus basin of Pakistan in terms of structure and stratigraphy using seismic data with some borehole information. In this paper, conventional integrated geophysical technique has been used to analyze the seismic data to characterize reservoir formations. To pursue the interpretation, 2D seismic data in SEG-Y format was used along with velocity and well logs information. Visual interpretation of seismic profiles is transformed into $2 \mathrm{D}$ and 3D (Time and Depth domain) contour maps, which is the representation of true subsurface geology. Three promising closures at shallow time have been identified on structural contour maps which are indicative of possible prospects. A closure, covering approximately $1 \mathrm{Sq} . \mathrm{Km}$ area over Eocene aged Sui Main Limestone and further two over Cretaceous aged Lower Goru formation covering areas of 500 and 400 Sq. km along shot point 260 and 380-390, respectively. Conjugate normal fault system among the stratigraphic layers existing in the study area can smoothly provide the hydrocarbon trapping mechanism. In order to further confirm the probable future prospects and support the study, modeling of $\mathrm{P}$ and $\mathrm{S}$ wave Acoustic Impedance have also been done. The advance integrated study of AVO modeling and numerical rock physics analysis may be helpful in providing further insights into current research.
\end{abstract}

Keywords Acoustic Impedance, Compressional and Shear Waves, Structural Interpretation, Lower Indus Basin Pakistan

\section{Introduction}

The study area having coordinates $26^{\circ} 52^{\prime} 50^{\prime \prime} \mathrm{N} \& 68^{\circ} 55^{\prime}$ $60^{\prime \prime} \mathrm{E}$ lies in Lower Indus Basin of Pakistan which is one of the proven geological provinces as well as contributing in the oil and gas requirements of the country. The study area has a prominent position in hydrocarbon prospecting with Sargodha high, Indian Shield and marginal zone of Indian Plate in north, east and west respectively,[1] furthermore, Tajjal gas field is situated in Sindh Province of Pakistan, discovered in 1991 and came in regular production after successful drilling of three wells in 1995. The production from this field on regular basis is in the form of gas with condensate while it is bounded by nearby famous gas fields namely Miano and Sawan. Major basins in Pakistan are result of two regional tectonic activity about 200 M.Y. ago, continuous rifting gave birth to formation of Lower Indus basin, which was further subdivided into two parts because of rotation of Indian plate about 55 M.Y. ago. In the original 1992 Field Development Plan the core area, which is the eastern part of the field Lower Goru was considered more prospective as the reservoir. [2]

Seismic interpretation is the processes of transforming seismic data into geological section to get information about structure and stratigraphy. It possibly will find out the general information about an area, locate prospects for drilling new exploratory wells, or guide development for already discovered field. According to, [3]there are two main approaches for interpreting seismic data, one is stratigraphic analysis and another is structural analysis. Stratigraphic analysis comprises of interpreted seismic section where the different lithological layers exhibit as genetically related sedimentary succession. Structural interpretation involves identifying proper geological structures for probable accumulation of hydrocarbon, mainly tectonics play vital role in structural styles of a geological entity. Tectonic setting usually governs the structural network and associated features. The Lower Indus basin of Pakistan has been resulted due to large scale extensional 
tectonic forces that resulted into normal faulting and associated horst and graben geometry. Structural traps include the faults, anticlines and duplex etc. [4] one of the most common ways of identifying seismic reflections is to compare a seismic section with another section to find the regularity in different horizon of the area to be investigated. To grasp strong command on seismic interpretation and structure delineation, synthetic seismograms are frequently used to identify the reflectors. [5] For new prospects in any area, seismic data interpretation for hydrocarbon traps is not sufficient, further detail study like Petro physical analysis, reservoir characterization, rock physics analysis and seismic modeling is required. According to [6] in order to get detail information of the subsurface, velocity modeling is indeed essential. However, if the geophysical data is sparse, then structural and stratigraphic interpretation is the most suitable method to extract more information regarding petroleum system. In general, velocity increases with depth as density and overburden pressure increases, velocity in the subsurface varies in both laterally and vertically. Vertical variations are due to lithological changes of layering and increasing pressure due to increasing depth.[7] Lateral variations are due to slow changes in density and elastic properties due to changes in lithology or physical properties. Meanwhile acoustic impedance provides useful information about the lithological successions as well as variation in different rock properties. [8, 9] Acoustic impedance variations are directly related to the lithological variations and hydrocarbons content in a reservoir formation."

A 60 fold 2D seismic data with 6 seconds of record length was acquired in 1989 by LASMO oil Pakistan limited in SEG-Y format. The seismic data for this study was provided in post stack migrate (PSTM) format for structural and strati graphical interpretation. In this study, we have interpreted the data of 2D seismic lines for better understanding of structure and stratigraphy in Lower Indus basin Pakistan. The horizons of interest are defined on the basis of their seismic character and continuity as well as wells formation top. Three seismic horizons were interpreted in the study area as Eocene aged Sui Main Limestone; Cretaceous aged Upper Goru and Lower Goru formations. For further insight, $\mathrm{P}$ and $\mathrm{S}$ wave acoustic impedance were numerically computed and modeled to locate probable hydrocarbon bearing prospects in the study area.

\section{Geological Setting}

Based on the sedimentation history and structural style, the Indus Basin is divided into three segments namely Upper, Central and Southern Indus basins. [10,11] Relatively high areas from shoreline of Jacobabad-Khairpur and MariKandhkot highs distributed the lower portion of Indus basin in central and southern basins mutually known as Sukker Rift.

The study area is situated on the eastern and southeastern flank of the regional north-south- trending
Jacobabad-Khairpur high as shown in Fig 1, which is an important factor in the formation structural traps in the study area,[12] Kadanwari, Sawan and Tajjal gas fields. The Jacobabad-Khairpur has been developed by dome uplifting during the early Cretaceous, and later on along deep seated faults in the Late

Cretaceous and Paleocene ages: The three tectonic events mainly responsible for the structural configuration of the study area are: First is the late Cretaceous uplift and erosion, Second event is a late Paleocene right-lateral wrenching, and third one is the late Tertiary to Holocene uplift/inversion of the Khairpur high. [10] The Khairpur high can be characterized by a high geothermal gradient of up-to $4.8^{\circ} \mathrm{C} / 100 \mathrm{~m}$ (328 ft.).[11] The study area has been evolved through above mentioned tectonic events and as a result the stratigraphic successions from Pre-Camb-Mesozoic and Paleogene have been deformed by more than one episode.[10] The variations can be seen in stratigraphic succession of Lower Indus basin from east to west, as no succession older than Late Triassic have been drilled in the Southern Indus basin.[12] The stratigraphic package of the Jacobabad-Khairpur High includes Mesozoic ,Tertiary and Quarternary lithologies as shown in Fig 2. The major unconfirmity occurs between base Permian and base Tertiary and the presence of Jurassic rocks in the area show deposition in early rifting stage. During early collision in Paleocene Ranikot, clastics were deposited followed by Eocene carbonates including the important reservoir unit Sui Main Limestone in the study area. The Sui Main Limestone was deposited on a shallow water carbonate platform with sporadic influx of clastic materials. This unit is widely distributed on a Jaccobabad - Khairpur High and which could be considered as good hydrocarbon reservoirs. Medium to coarse-grained sandstones in a shallow-marine setting constitute the main reservoir (Lower Goru Formation) in the field. [11] The sandstone of the Cretaceous Lower Goru is the most productive reservoir rock unit in the study area and nearby oil and gas fields. The lower part of this member has informally been divided, from bottom to top, into $\mathrm{A}, \mathrm{B}$, and $\mathrm{C}$ intervals, respectively. [12]

\section{Petroleum Prospects}

The Lower Cretaceous formation (Lower Goru) has consecutive layers of sand and shale. These sands act as reservoir rock units with rapidly varying reservoir characteristics within few kilometers. The foremost influence on these two processes is the degree of sands supply. This formation is the most proven reservoir rock unit throughout the entire basin; it is producing oil and gas in many fields located in Lower Indus basin. The Eocene aged Sui Main Limestone is also found productive in the vicinity gas fields. The shales of Cretaceous and Eocene act as source rock units in the study area. [13]. 


\section{Seismic Coverage}

The study area is an old exploration concession known as Old Tajjal Concession situated in the Lower Indus basin. The initial 2D seismic data in investigated area was acquired 6 to 7 kilometers along a horizontal profile in the year 1988 . The seismic profiles are generally east west trending with some lines ties in north south direction. The prospective areas were subsequently in-filled with more data; the current study area is one of them, in which the central area was considered more prospective than western area. In the year1989, a NE-SW orientated, 2 kilometers spaced seismic grid, with a shot point interval of $50 \mathrm{~m}$ and 60 -fold coverage was acquired. This was extended in 1990 to the west, but with a $25 \mathrm{~m}$ shot point interval and 120 -fold coverage. The seismic source used was vibroseis. The area is generally covered with sand dunes of Thar Desert. [10]

\section{Materials and Methods:}

For seismic data interpretation, the identification of seismic reflection packages has been done using seismic sections as shown in Fig 3 ( $a, b$ and $\mathrm{c}$ ), depths from formation tops and average thicknesses from available wells, interval and average velocities during the processing of seismic data, geological and seismic characteristics of different lithologies. Faults on the seismic sections are recognized on the basis of discontinuity in the subsurface seismic reflections falling along an essential linear pattern, mis-closure in tying reflections around loops, divergence in dip not related to stratigraphy, diffraction patterns mainly those with vertices, which line up in a manner consistent with local faulting, distortion or disappearance of reflections below suspected fault lines.[3] In stratigraphic interpretation, lateral continuity, variation in sedimentary deposits and different episodes of sedimentation affected by tectonic activities and recognition of time depositional units is studied.

In this study, we investigated new prospects for fast track implementation of oil and gas exploration activities in parts of Lower Indus basin of Pakistan. Regional geology, tectonics and stratigraphy were reviewed as part of the objectives in order to properly identify the structural and stratigraphical traps which were then confirmed by compressional and shear wave's velocity and Impedance modeling. On the basis of structural and stratigraphic trends of the formations and geological history, migration pathways are also predicted along deeper horizon on seismic section as shown in Fig 3b. The Iso-velocity map commonly shows velocity variations along horizontal and vertical directions over a specific profile was constructed using velocity information obtained from seismic sections.

The primary objective of seismic interpretation is therefore to prepare contour seismic maps showing the two way time to a reflector as picked on the seismic sections. This time isochronal map must be converted to depth map through the seismic time-depth conversion process. Contour maps are the most accurate representative of subsurface geology; consequently interpreted seismic sections along with average velocity information were used to generate 2D \& 3D contour maps of formations of interest in the study area. The contour maps of Lower Goru formation and Sui Main Limestone are shown in the Fig $5 \& 6$ respectively.

Trace Envelope as attributes analysis has the ability to enhance strength, amplitude and energy of the reflector while increasing the basic properties of seismic reflectors. Trace Envelope was initially developed for the oil industry by Nigel Anstey in the 70's in order to identify "bright spots" related to hydrocarbon accumulations. Trace envelope can be computed from complex trace which was first introduced by [14] the complex trace can be defined as;

$$
C T(t)=T(t)+\imath H(t)
$$

Where;

$$
\begin{aligned}
& C T(t)=\text { complex trace } \\
& T(t)=\text { seismic trace } \\
& H(t)=\text { Hilbert's transform of } T(t) \\
& H(t) \text { is a } 90^{\circ} \text { phase shift of } T(t)
\end{aligned}
$$

The Trace Envelope is calculated from complex trace by the following formula;

$$
E(t)=S Q R T\left\{T^{2}(t)+H^{2}(t)\right\}
$$

Trace envelop is helpful in identifying the subsurface discontinuities, lithological variations, changes in deposition system and sequence boundaries. In order to differentiate the top and bottom of various geological units or formations in the study area the trace envelope was designed using seismic lines.

An empirical relationship was established for computation of acoustic impedance by using density and velocity information. This relationship is widely used for brine saturated sedimentary rocks and is given in $\mathrm{Eq}$ (3);

$$
\begin{gathered}
\rho=.23 V_{p}^{.25} \\
V_{s}=\sqrt{\frac{\mu}{\rho}}
\end{gathered}
$$

Where;

$$
\rho=\operatorname{density}\left(\mathrm{g} / \mathrm{cm}^{3}\right)
$$

$V_{p}=$ P-wave (compressional) velocity ( $\left.\mathrm{ft} / \mathrm{s}\right)$

\section{$\mu=$ Shear Modulus}

Consequently, the acoustic impedance can be computed by using the compressional and shear wave velocity information, the empirical relation between velocity and density is given by;

$$
Z=V_{p, s} \rho
$$

$Z=$ Acoustic Impedance 
Root Mean Square (RMS) velocity read from velocity panels of the seismic data provided were used to derive different velocities using Dix equations to construct compressional and shear wave's models, density sections and impedance sections. The impedance sections for P \& S waves were created after numerical solution for available velocity data as shown in Eq (5). To achieve this target, SMT Kingdom 8.4 and Geosoft (Oasis 2012) software was used in integration with other Geological and Geophysical software.

\section{Results and Summary}

Structural and stratigraphical interpretation of a geological entity is important for expediting hydrocarbons exploration. In order to understand the subsurface geology and structural trends for possible hydrocarbon prospects in the study area, seismic data with some well information were used on an interactive workstation. Distinguishable results have been achieved by using 5 seconds two way travel time data to explore the hydrocarbon potential of the geological structures a part of Lower Indus basin Pakistan. The structural interpretation of the seismic data is presented in
Fig 3. Based on the well to seismic ties three horizons were identified in the seismic sections. These three horizons were named Possible Sui Main Limestone, Possible Upper Goru and Possible Lower Goru formation. The fault analysis was carried out on dip lines because it provides clearer picture of the fault pattern. Figure 3 (a) shows an interpreted seismic line oriented NE-SW direction. The green, purple and blue colors represent Possible Sui Main Limestone, Possible Upper Goru and Possible Lower Goru formation. Faults are marked as black in order to differentiate between horizon and fault as it is discontinuity in seismic reflectors. Since the study area is an extensional regime disturbed by drifting with some rotational component therefore the interpretation results show that the area has normal nature of faulting with some wrench components. The associated geometry is horst and graben, horst is geologically uplifted part of the normal fault while graben is the down ward portion of the fault which is bounded by two normal faults. Graben is relatively deep portion, where chances of hydrocarbon accumulations are less. Each horizon/formation show horst and grabens geometry, since hydrocarbons always move from high potential or high

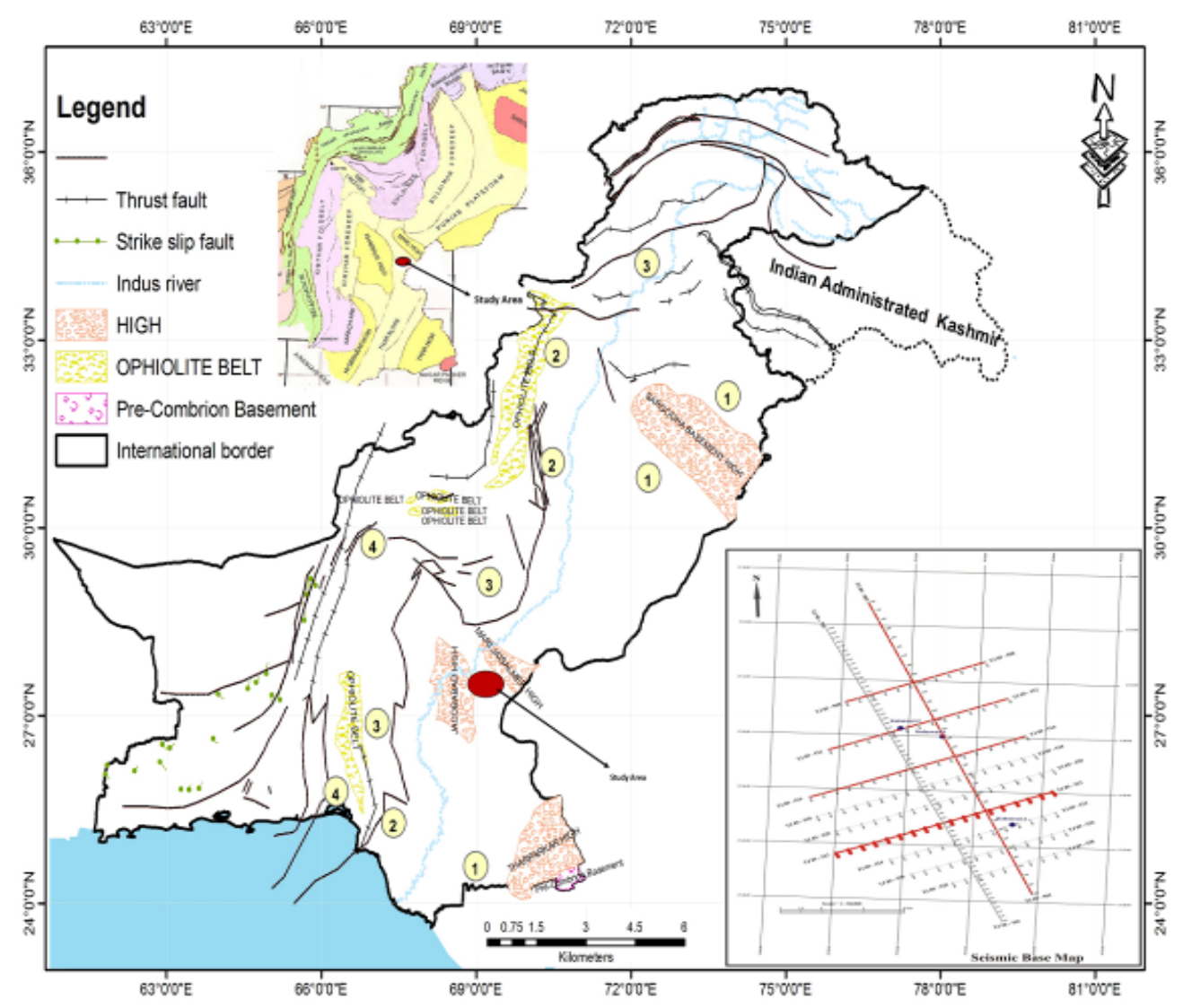

Figure 1. Geological and Tectonic setting of Lower Indus Basin Pakistan (modified after Kazmi \& Rana, 1982). The Base map in the bottom right corner shows the seismic profiles. The study area is highlighted by circle. 


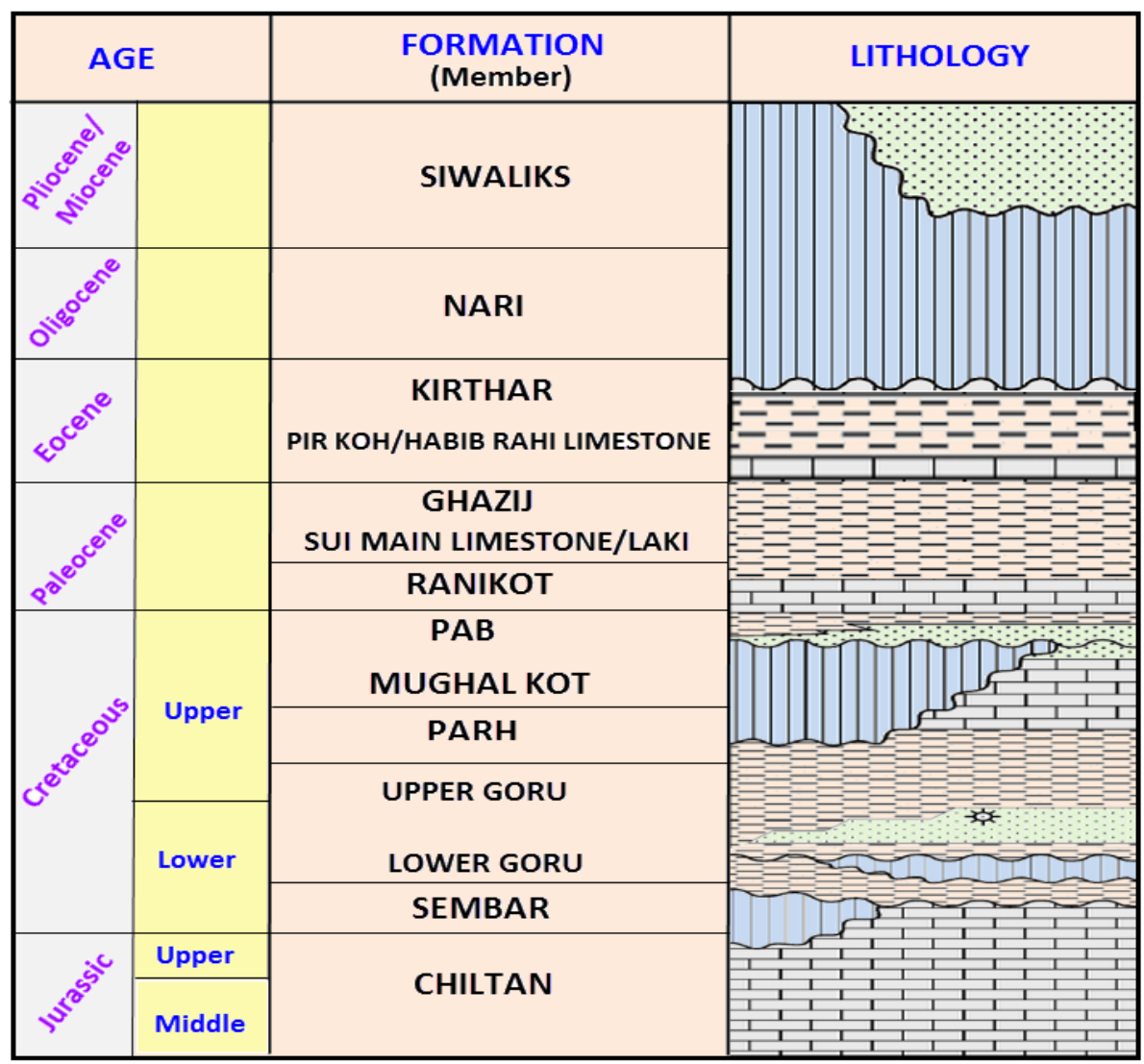

Figure 2. The generalized stratigraphy of Lower Indus basin, Pakistan. The formations shown are mainly from the present study area.
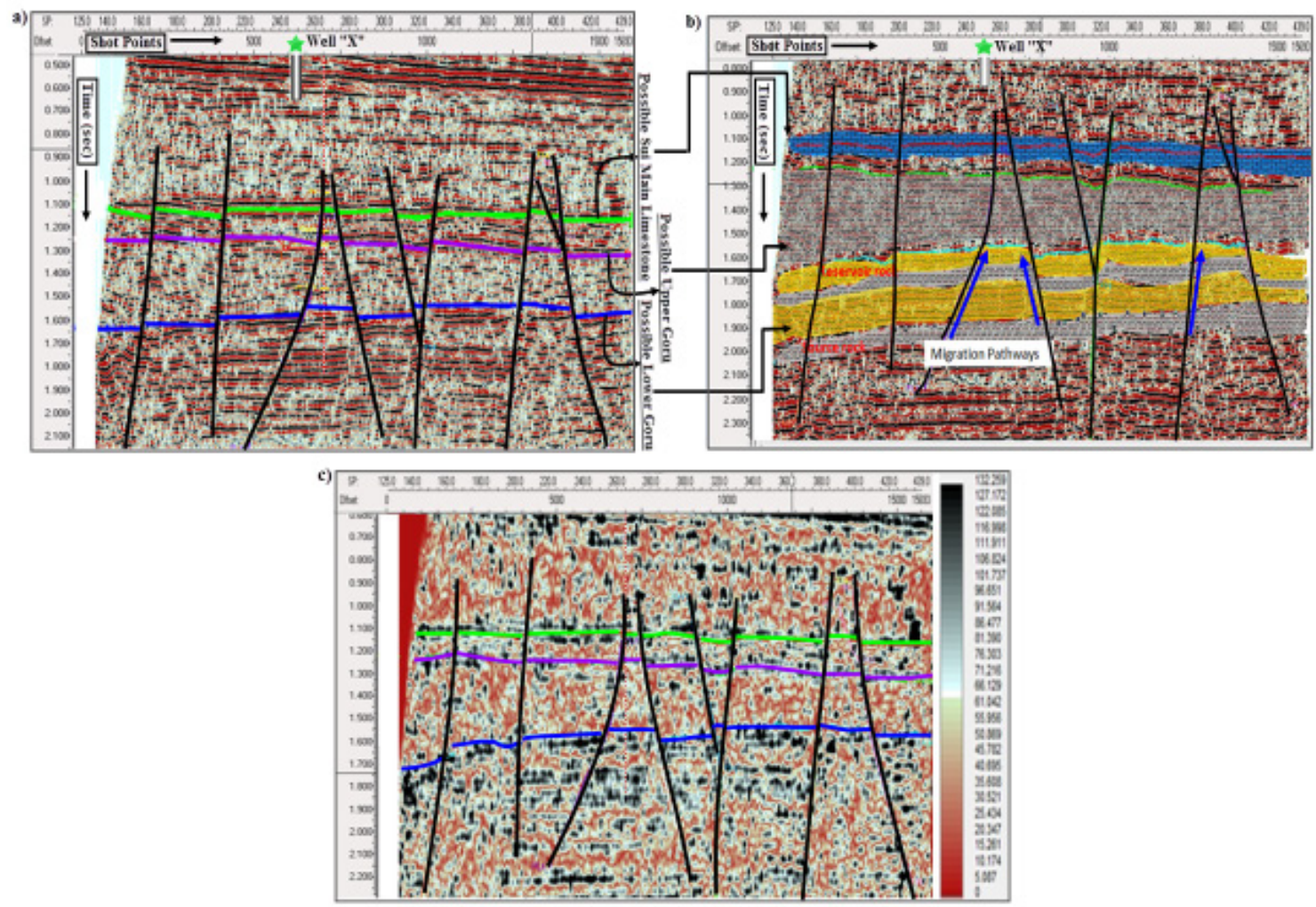

Figure 3. Interpreted seismic lines showing normal faulting with horst and graben geometry (a) lithologies filled and predicted hydrocarbon migration path (b) \& (c) Trace Envelope map of seismic line "X". 
Pressure area to low potential or low pressure area therefore the probability of hydrocarbons accumulation is mainly possible on "horst" rather than graben. Pressure in Horsts structure is comparatively low as compared to grabens because of the fact that horsts are shallow portions as compared to grabens in entire structure. The traps in the study are mainly stratigraphic traps. Sui Main Limestone (SML) and Lower Goru formation have strong reflection on the seismic section. A number of normal faults can be seen on the seismic section. SML formation is not much disturbed by faults on the western sides of the seismic section. But if we go deeper in the seismic section the throw of the faults increases. A very minor horst structure at Sui Main Limestone (SML) level can be seen on the seismic section between Shot Points 380 to 395 at approximately 1.138 seconds. Fig 3 (b) shows lithologies filled in respective formations, it is close to real situations in the subsurface, predicted path for migration of hydrocarbons is shown with blue color arrows. Once the hydrocarbons are matured within the source formation (Shales of Lower Indus basin: probably Sembar formation), they are migrated towards the Lower Goru formation (reservoir formation) through these predicted paths. Generally the primary migration takes place along the fault or fractured planes or pores within rock units. Envelope map for the known seismic line is shown in the Fig 3 (c). Trace envelope rose with ultimate energy horizon on seismic section and often associated with huge hydrocarbon accumulation in the form of bright spots. It is affected by the slope, rather than envelope magnitude, hence indicate sharp interfaces.

Fig 4 shows the Iso-velocity contour map of the study area. The Iso-velocity contour map represents the lateral as well as vertical variations encountered in the study area. In practice, these variations are resulted due to changes in the rock properties and discontinuities affected by tectonic force and over burden pressure. This map shows the push-up and pull-up velocities. These velocities are representative of variation of average velocities at certain time along different vibrating points. The purple color represents low velocities associated with shallow subsurface unconsolidated sediments while the red color represents higher velocities and deeper portions of the subsurface, it follows the general trend of velocity increase with increase in depth. The Iso-velocity map is important for current study in order to observe anomalies associated with structural disturbances in the study area.

Contours represent the lines joining the same elevation so they are important tool of seismic data interpretation. Contours represent the picture of the subsurface formations. It is generally applied to basin wide study because data in time or depth domain of all the seismic lines are used to contour a single formation. Time and depth contour maps of Sui Main Limestone and Lower Goru in 2D and 3D are shown in Figs 5 \& 6 (a-d).

Figure 5 represents the time and depth contour maps of Sui Main Limestone, the yellow color shows the shallowest part (horst) and blue color shows deeper parts (graben). A closure of light yellow contour having $0.05 \mathrm{sec}$ interval at shallow time of $1.125 \mathrm{sec}$ covers approximately area of 1 square kilometer.Well " $\mathrm{X}$ " is drilled at the extreme eastern boundary on the horst structure. Contour value lies between $1.110 \mathrm{sec}-1.179 \mathrm{sec}$, complete structure of the area has been covered by this interval of two way travel time. The highlighted area in the same Figure may be the probable zone of hydrocarbon accumulation, because it provides a good stratigraphic and structural trap. The time contour map of Sui Main Limestone was converted into depth domain using the information of average velocity in the study area. The contour map of Sui Main Limestone is shown in depth domain in Fig 5 (b), the depth ranges from 1221 to 1297 meters and geometry is same as the time domain. Figure 5 (c) and (d) show 3D representation of the time and depth contour maps of Sui Main Limestone.

Contour maps of Lower Goru formation are shown in Figure 6. The contour mapping of 0.05 seconds contour interval shows a closure of $500 \mathrm{sq} \mathrm{km}$ at Shot Point \# 260 of two horst structures with approximately 0.1 seconds vertical throw and in terms of depth it is approximately 15 meters. A small lead is also present at Shot Point $380-390$ of closure $400 \mathrm{sq} \mathrm{km}$ bounded by fault towards western side of the Lower Goru formation. This could be very good promising zone for accumulation of hydrocarbons and can be regarded as future prospects. 3D contour maps of Lower Goru formation is also shown in the Fig 6 (c and d). The maps clearly depict that area has conjugate normal fault system with extensive horst and graben geometry.

Figure 7 shows the velocity modeling of the simple body wave propagation and acoustic impedance sections of a seismic profile "A". The interval velocity information was used to investigate the variations of compressional and shear wave and their response to different formations. Velocities generally increase with depth, tight sand show sharp increase while shales generally show blunt variations in seismic velocities. In seismic, velocity information play vital role in providing the subsurface details. Figure 7 (a and b) show a velocity trap between 2500 to 3500 mill-seconds, throughout the section the velocity of both $\mathrm{P}$ and $\mathrm{S}$ waves uniformly increases with depth but the highlighted zone shows a trap of intermixed velocity which depicts a transition or presence of gas sand inside the formation. The trap was confirmed with acoustic impedance model for the same profile as well. In Fig 7 (c and d) the sky and pink color represents zones of high acoustic impedance while blue color represents low acoustic impedance contrast. The zone between 2500 to 3500 mill-seconds may be the possible future prospect. The same

Zone was marked in contour maps of Lower Goru Formation (Main Reservoir rock in study area); both the structural and stratigraphical interpretation and seismic wave's propagation models confirm an anomalous zone.

Figure 8 shows the compressional and shear wave propagation model and impedance sections for the seismic profile "B". According to, [15] the trapping of seismic waves in the subsurface always depicts presence of fluid inside the 
rock formation. The same anomaly was seen close to 2500 mill-seconds as marked by the circle in Fig $(8 \mathrm{a}, 8 \mathrm{~b})$, the same anomaly was seen in the impedance sections of the same profile. The zone may be considered promising for future exploration.

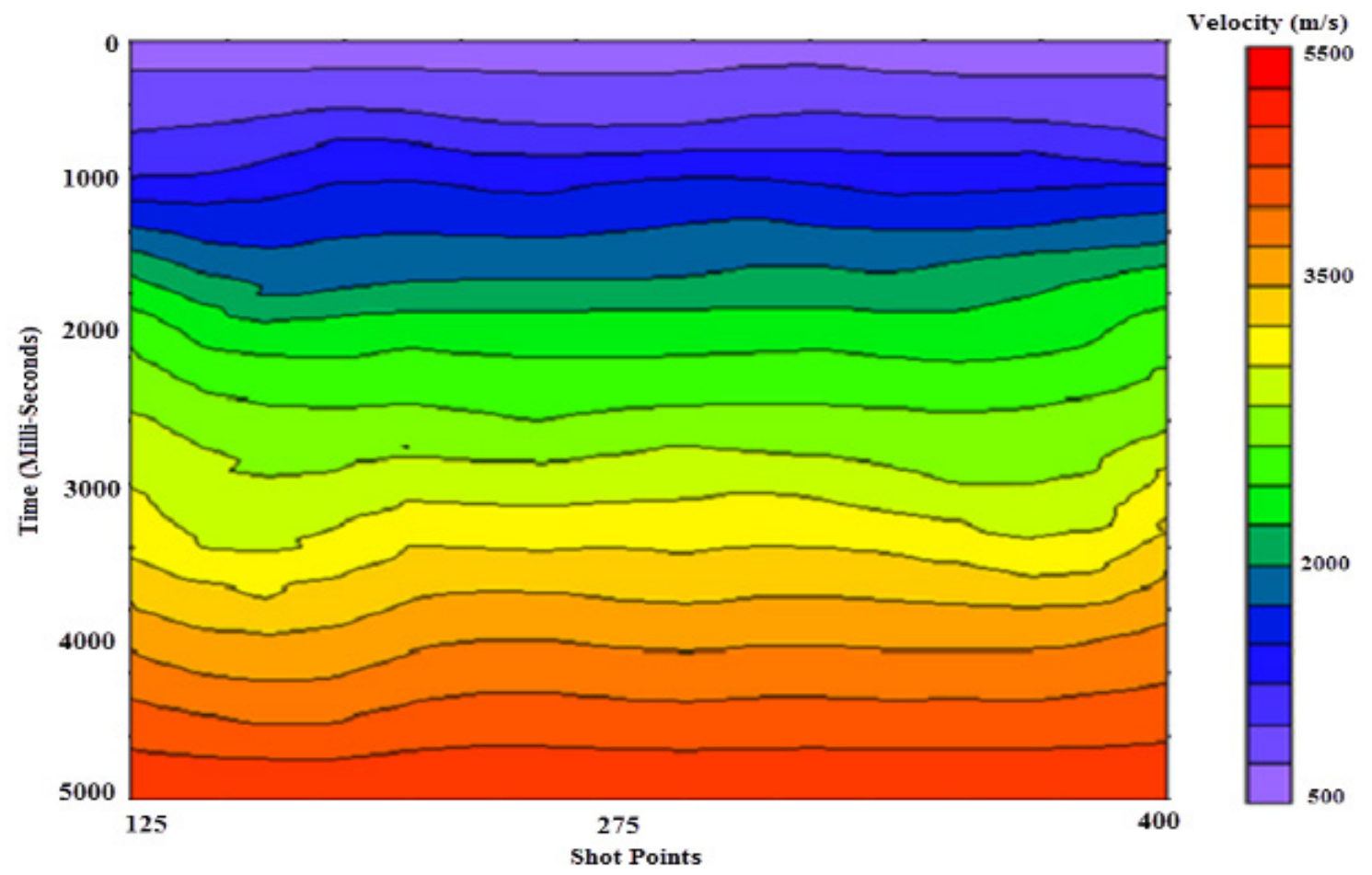

Figure 4. Iso velocity contour map with shot points distributed on horizontal axis while TWT (mill-seconds) on vertical axis. Blue color shows low velocities and red color shows high velocities.
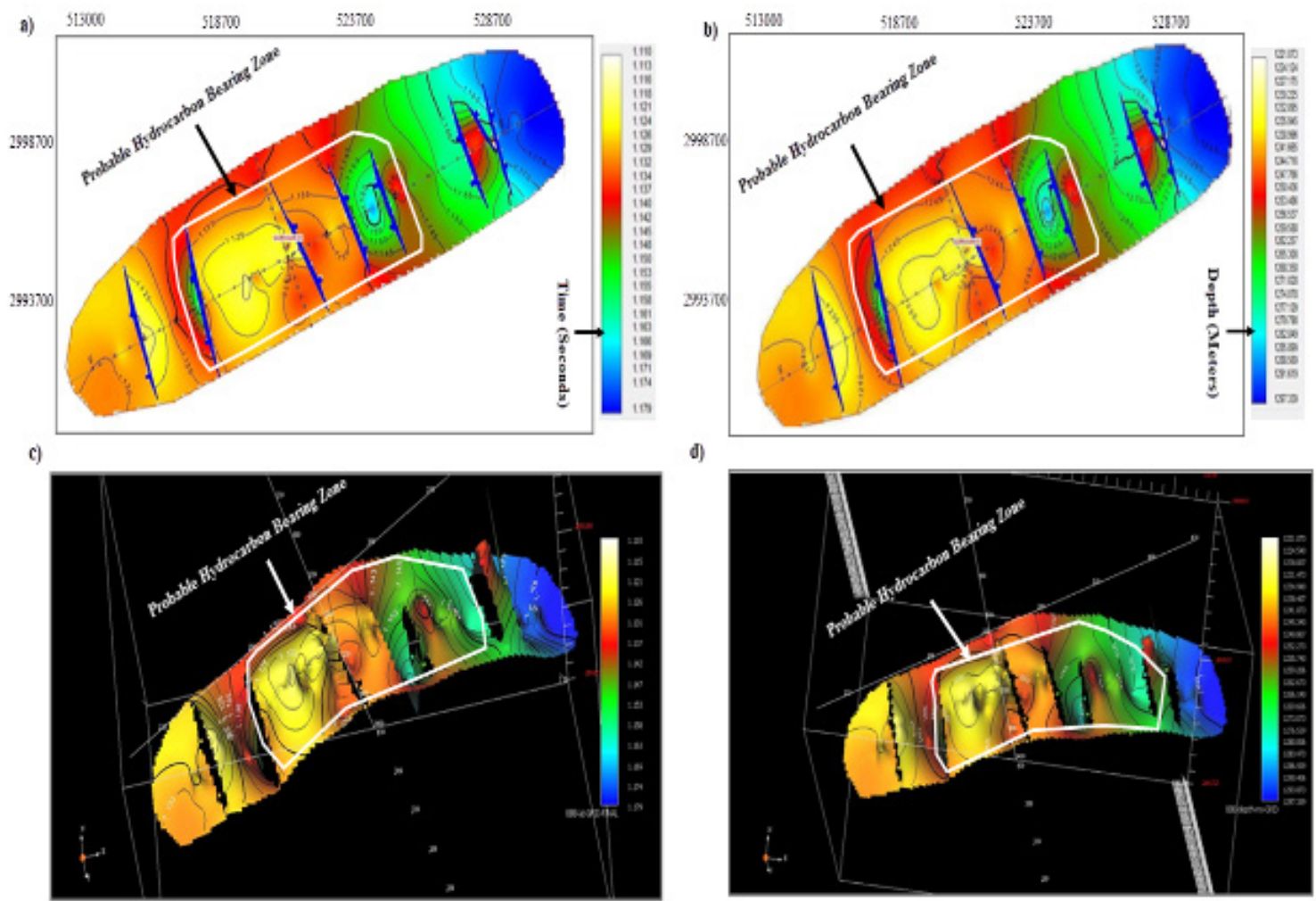

d)

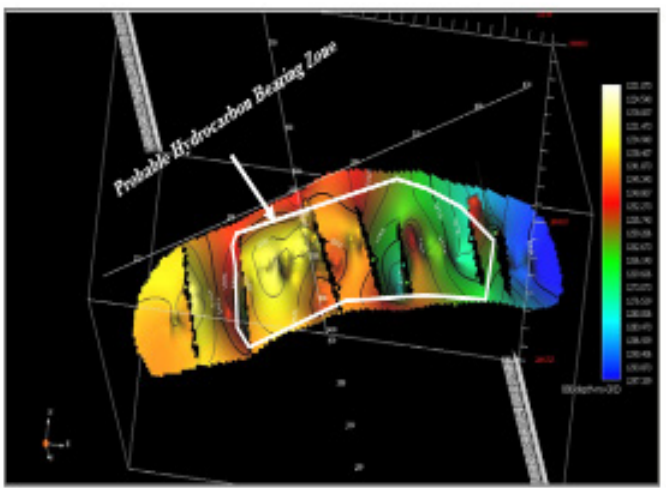

Figure 5. 2D Time contour map of Sui Main Limestone (a) 2D depth contour map of Sui Main Limestone (b) 3D time contour map (c) 3D depth contour map of Sui Main Limestone 

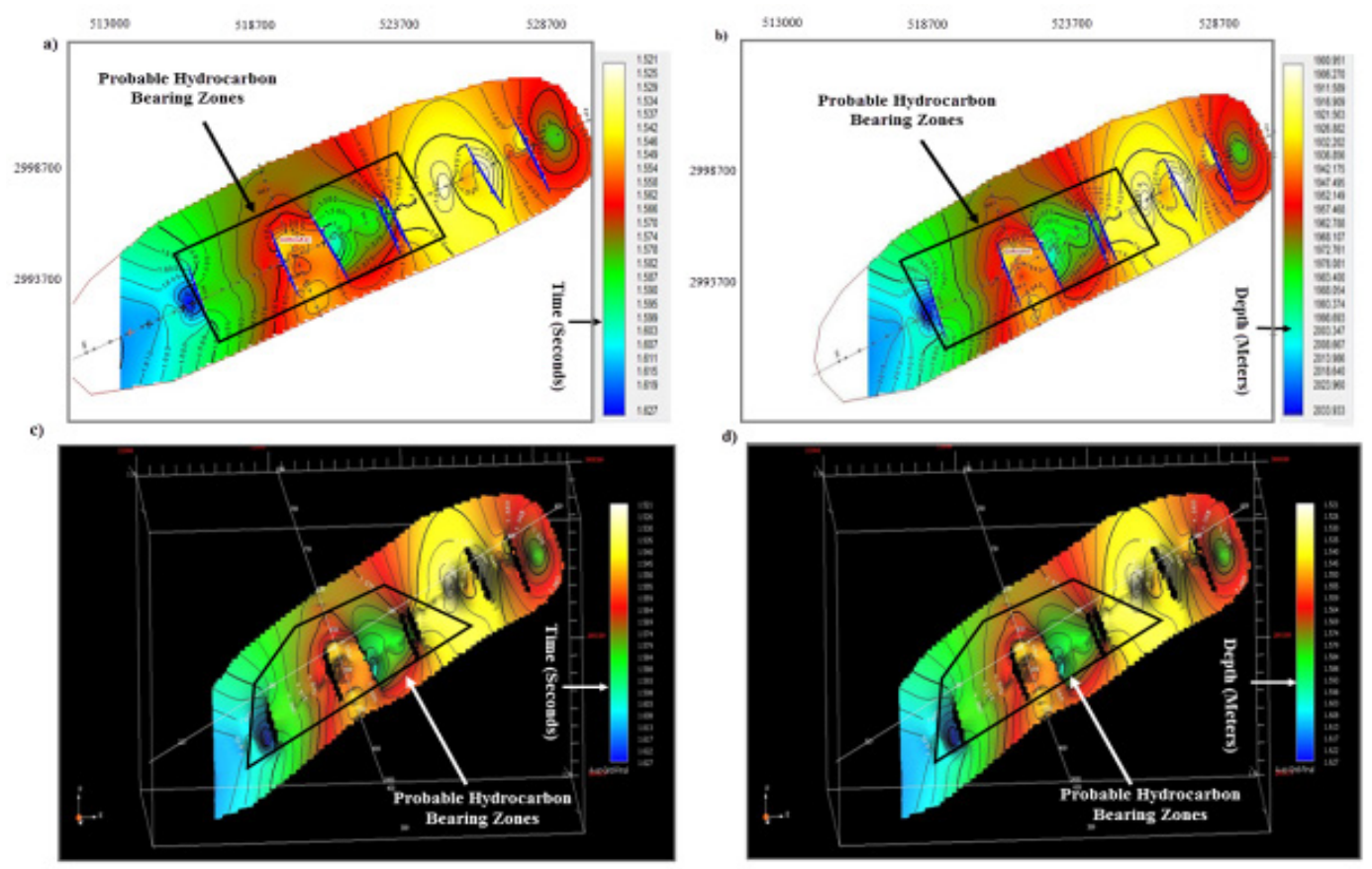

Figure 6. 2D Time contour map of Lower Goru Formation (a) 2D depth contour map of Lower Goru formation (b) 3D time contour map (c) 3D depth contour map of Lower Goru formation
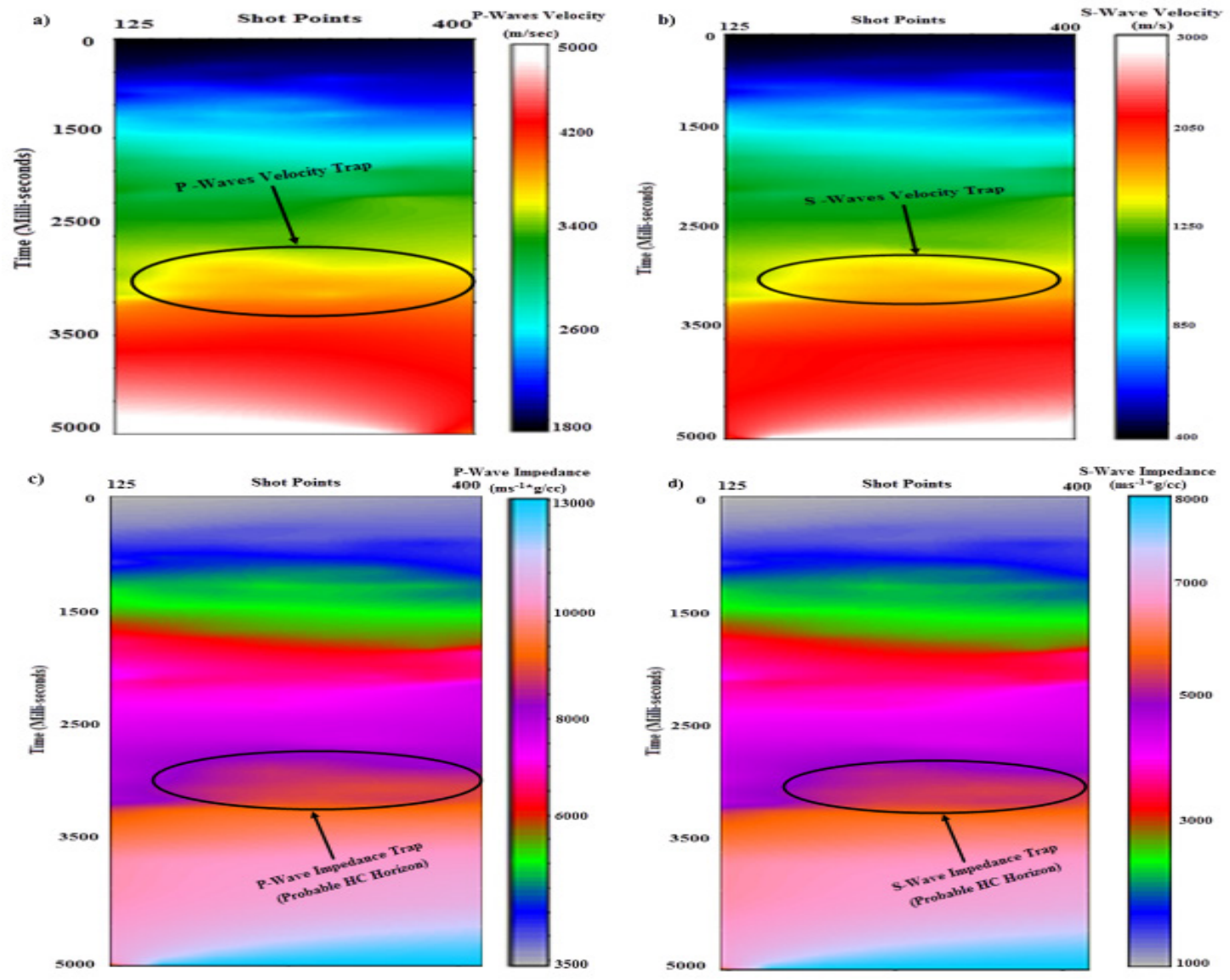

Figure 7. Models of Compressional and Shear waves Acoustic Impedance for seismic profile "A". Compressional wave velocity model having a possible trap between 2500 to 3500 mill-seconds (a) Shear wave model (b) Compressional wave Acoustic Impedance with impedance trap between 2500 to 3500 mill-seconds (c) Shear wave acoustic Impedance. 

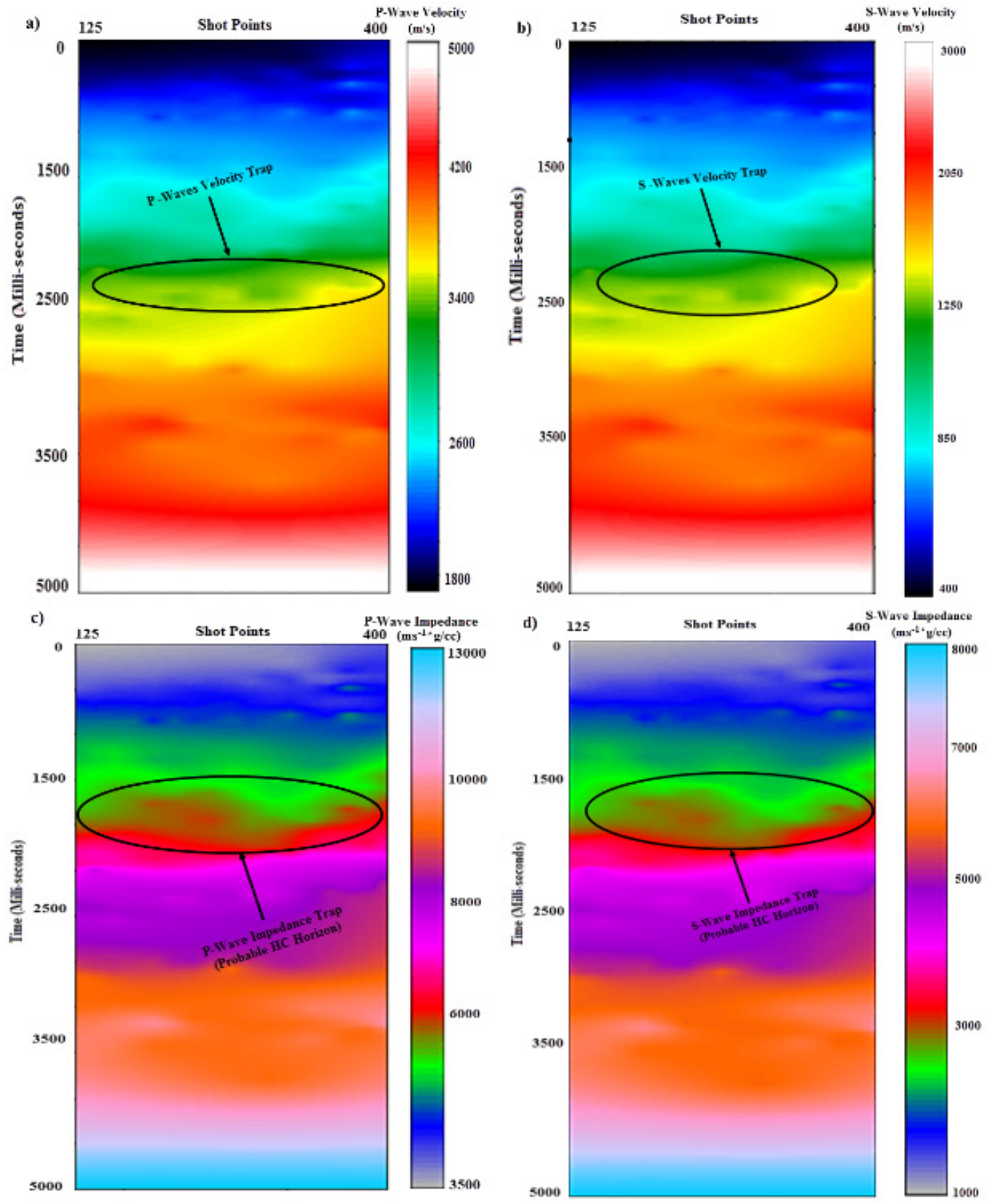

Figure 8. Models of Compressional and Shear waves Acoustic Impedance for seismic profile "B". Compressional wave velocity model having a possible trap between 1500 to 2500 mill-seconds (a) Shear wave model (b) Compressional wave Acoustic Impedance with impedance trap between 1500 to 2500 mill-seconds (c) Shear wave acoustic Impedance.

\section{Conclusions}

The structural and stratigraphical based seismic interpretation of possible hydrocarbon bearing formations in a part of Lower Indus Basin has been done using integrated approach of reflection seismic profiles, geology and acoustic impedance modeling. Three horizons have been marked on the basis of available information of well " $\mathrm{X}$ ". The structural analysis of seismic profiles $\mathrm{A}$ and $\mathrm{B}$ shows conjugate normal fault system which are responsible for hydrocarbon entrapment in field. A closure of contour at shallow time of $1.125 \mathrm{sec}$ on Eocene aged Sui Main Limestone covers an area of approximately $1 \mathrm{Sq}$. Km, while for Lower Goru formation a closure of $500 \mathrm{Sq}$. Km at Shot Point 260 of two horst structures with approximately $0.1 \mathrm{sec}$ vertical throw and in terms of depth it is approximately 15 meters and another closure is of $400 \mathrm{Sq}$. Km between Shot Point 380-390. We have concluded that about 50 M.y ago tectonic 
deformation in the study area has resulted variety of structural and stratigraphical traps. Based on our findings, the Lower Indus basin can be regarded as unique for hydrocarbon accumulations. The compressional \& shear waves and impedance modeling show the same anomalous zone as depicted by seismic data interpretation. The acoustic waves modeling investigation show the prospective to include the appropriate information of subsurface geological and geophysical understandings. We are interested in lengthening this approach for further studies with good quality data in order to facilitate the researchers as well as industry professionals for expediting hydrocarbons exploration and exploitation in Lower Indus basin of Pakistan. This study, however, can provide additional information for precise well placement in further exploration and production of oil and gas. Within the limits of the available data, it is recommended that further studies should include integration of velocity (check shot) and bio stratigraphic data of all the wells. This will provide more reliable data for interpretation of the depositional environments.

\section{Acknowledgements}

We are thankful to Directorate General of Petroleum Concessions, Ministry of Petroleum and Natural Resources, Islamabad Pakistan for providing the public domain data set.

\section{REFERENCES}

[1] [1] Kazmi, A. and Rana, R. 1982. Geology and Tectonic of Pakistan, Graphic publishers Karachi Pakistan, Geological Survey of Pakistan.

[2] Ahmad, N. and Chaudhry, N. 2002. Kadanwari gas field Pakistan a disappointment turns into an attractive development opportunity Petroleum Geoscience, 8(4), 307-316.

[3] Badley, M. E. 1985. Practical seismic interpretation Boston International Human Resource Development Corporation, 266.

[4] Sheriff, R. 1999. Encyclopedia Dictionary of Exploration Geophysics Society of Exploration Geophysics, Edn 3.

[5] Coffeen, J.A. 1984. Seismic Exploration Fundamentals, Penn Well Publication Company.

[6] Robinson, E. S. and Coruh, 1988. Basic Exploration Geophysics, John Wiley.

[7] Lillie, R. 1999. Whole Earth Geophysics: An Introductory Textbook for Geologists and Geophysicists, Prentice Hall.

[8] Lavergne M., 1975. Pseudo diagraphies-de vitesse en offshore profound, Geophysics Prospecting, 23,695-711.

[9] Lindseth R. O., 1976. Seislog process uses seismic reflection traces, Oil and Gas Journal, 74(43), 67-71.

[10] Ahmad, N., Mateen J., Shehzad Ch., Mehmood N. and Arif F., 2012. Shale Gas Potential of Lower Cretaceous Sembar Formation in Middle and Lower Indus Basin Pakistan, Pakistan Journal of Hydrocarbon Research, Edn22, 51-62.

[11] Berger A., Gier S. and Krois P., 2009. Porosity-preserving chlorite cements in shallow-marine volcaniclastic sandstones Evidence from Cretaceous sandstones of the Sawan gas field Pakistan, AAPG Bulletin, 93(5) 595-615.

[12] Krois, P., Mahmood Tand, Milan, G., 1998. Miano field, Pakistan, a case history of model driven exploration: Proceedings of the Pakistan Petroleum Convention, Pakistan Association of Petroleum Geologists, Islamabad 111-131.

[13] Kadri, I., 1995. Petroleum Geology of Pakistan, Pakistan Petroleum Limited.

[14] Taner, M., Koehler, F. and Sheriff, R., 1979. Complex seismic trace analysis Geophysics. 44, 1041-1063.

[15] Castagna, J., Batzle, M., and Eastwood, R., 1985. Relationships between compressional wave and shear-wave velocities in clastic silicate rocks Geophysics, 50, 571-581. 